\title{
Políticas de Tecnologias da Informação e da Comunicação e democracia no Ceará
}

\author{
Gabrielle Dannunzio Cavalcanti Moreira \\ Universidade Estadual do Ceará - UECE \\ Prof. Dr. Alexandre Almeida Barbalho \\ Universidade Estadual do Ceará - UECE
}

\begin{abstract}
Resumo
Este artigo analisa as Políticas de Tecnologias da Informação e Comunicação (TICs) implementas pelo governo do Ceará nas gestões de Cid Gomes (2007-2010; 2011-2014) e Camilo Santana (2015-2018) objetivando avaliar até que ponto estas políticas foram pensadas como ferramentas de fortalecimento da democracia. Optou-se por fazer uma análise documental, tanto interna, que procura extrair as linhas fundamentais e secundárias dos documentos, quanto externa, contextualizando-os dentro da lógica política que lhes originou. Concluiu-se que houve alguns ganhos democráticos, mas aqueles voltados à eficiência administrativa foram de fato o principal foco da política de TICs.
\end{abstract}

Palavra-chave tecnologias da informação e comunicação; política púbica; democracia; ceará

\begin{abstract}
This article analyzes the Information and Communication Technologies Policies (ICTs) implemented by the government of Ceará in the administrations of Cid Gomes (2007-2010; 2011-2014) and Camilo Santana (2015-2018) in order to evaluate the extent to which these policies were thought as tools for strengthening democracy. We opted to make a documentary analysis, both internal, which seeks to extract the fundamental and secondary lines of the documents, as well as external, contextualizing them within the political logic that originated them. It was concluded that there were some democratic gains, but those aimed at administrative efficiency were in fact the main focus of ICT policy.
\end{abstract}

Key-word information and communication technologies; public policy; democracy; ceara

\section{Introdução}

A ampliação dos canais de participação civil nas decisões governamentais é um importante passo para o avanço e aprimoramento da democracia, pois possibilitam a diversos setores da sociedade - principalmente os mais distantes das esferas do poder participar de algum modo da formulação, implementação e avaliação das políticas públicas. 
Neste sentido, as Tecnologias da Informação e Comunicação (TICs) ocupam lugar estratégico alterando radicalmente a qualidade das interações entre governo e sociedade e ampliando potencialmente o campo de atuação democrática.

As TICs, por exemplo, permitem acessos mais rápidos para o acompanhamento e levantamento das informações sobre prestação de contas, da origem à aplicação dos recursos financeiros, bem como o uso de canais direto de relacionamento - e-mails, formulários de perguntas e respostas, chats etc - entre Estado e cidadão, possibilitando maior grau de accountability e transparência. Maia, Gomes e Marques (2011) e Coleman e Spiller (2003), entre outros, observam como a internet contribuiu para criar uma entusiasmada expectativa de ampliação e revitalização da participação cidadã na esfera política e de fortalecimento da relação entre representantes e representados.

Contudo, esta relação entre TICs e ampliação da democracia não é automática. Como adverte Norberto Bobbio, o regime democrático "se encontra continuamente diante de obstáculos não previstos que precisam ser superados sem que se altere a sua própria natureza" (BOBBIO, 2017, p. 10). Leonardo Avritzer e Boaventura de Sousa Santos, por sua vez, chamam atenção para o fato de que "o modelo hegemônico de democracia tem sido hostil à participação ativa dos cidadãos na vida política e, quando a tem aceitado, tem-na confinado ao nível local" (AVRITZER; SANTOS, 2002, p. 73).

Isto implica reconhecer que o fato de que as TICs não estão necessariamente a serviço da resolução dos déficits democráticos. Pode ser, inclusive, que os resultados sejam o inverso, ou seja, a exclusão daqueles que são pouco familiarizados com as tecnologias digitais ou que simplesmente não possuem acesso a redes digitais, estabelecendo, paradoxalmente, uma nova elite, a dos conectados. Dessa forma, é importante analisar em cada caso empírico se e como estas ferramentas contribuem para o fortalecimento dos espaços do cidadão e do Estado de direito e a promoção da diversidade de agendas na esfera pública e nas instâncias de decisão política (GOMES, 2011; MARQUES, 2008). Ou se elas funcionam apenas como recursos para o fortalecimento da administração da vida (ADORNO; HORKHEIMER, 1986).

No caso brasileiro, o estabelecimento de novas legislações para acompanhamento e prestação de contas das ações governamentais (Lei Complementar n. 101 de 2000 - Lei de Responsabilidade Fiscal; Lei Complementar n.우 131 de 2009 - Lei da Transparência; e Lei de acesso à informação de 2011) impactou a administração pública, compelindo os governos federal, estadual e municipal a readequarem o seu modelo de governança visando publicizar suas ações e resultados de maneira transparente e tempestiva, tendo a internet como recurso fundamental.

Foi nesse contexto, por exemplo, que o governo do Ceará criou seu Portal da Transparência em 2007. Inicialmente, o portal cearense, como os das demais unidades federativas, tornou público as suas informações, conforme estabelecido nos dispositivos legais. Contudo, paulatinamente, ele ampliou sua oferta de serviços como os canais de relacionamento com a sociedade, visando colher contribuições para a melhoria das ações e implementação de novas ideias. Esta inovação foi reconhecida pelo Ministério Público Federal (MPF) que avaliou, por meio do Índice Nacional de Transparência (INT), os portais dos governos estaduais, tendo o Ceará sido classificado na primeira colocação em 2015, com o índice de transparência de 8,02, e em 2016. com o índice 10,00.

A boa performance do governo estadual no ranking do MPF coloca questões importantes ao pesquisador interessado no tema da democracia digital: por que um estado pobre, situado em uma região que o senso comum e mesmo algumas análises acadêmicas 
teimam em qualificar como "atrasada", "clientelista" e celeiro de oligarquias, se destaca na utilização de TICs para reforçar sua accountability?

Esta, sem dúvida, é uma pergunta de abrangência ampla que não pode ser respondida no escopo de um artigo. Contudo, é possível elaborar perguntas menos ambiciosas, mas igualmente relevantes, que podem auxiliar a entender esse contexto. Por exemplo, como o governo inseriu as TICs no âmbito da gestão administrativa do Estado? Elas funcionaram para favorecer um ambiente de reciprocidade com o cidadão na implementação de ações e/ou políticas públicas? Ou serviram apenas como ferramentas para levar adiante as reformas do Estado que vem se implantando no Ceará desde o final dos anos $1980 ?$

A discussão que segue procura responder a estas questões analisando as políticas de TICs dos governos Cid Gomes (2007-2010; 2011-2014) e Camilo Santana (2015-2018). A escolha por estas gestões se explica, primeiro, pelo fato delas serem contemporâneas às três leis citadas anteriormente e aos processos desencadeados desde então. Segundo, porque há uma alinhamento político entre estes governos e o governo federal, em especial no governo Santana, posto que seu titular é filiado ao Partido dos Trabalhadores (PT), o mesmo da então presidenta Dilma Rouseff.

Por fim, o recorte se justifica pelo fato destes políticos serem considerados como integrantes de um outro ciclo da política cearense, liderado pela família Ferreira Gomes, o que, hipoteticamente, significaria um rompimento com a política de reforma administrativa de cunho liberal dos governos anteriores, chamados de "governos mudancistas", liderados por Tasso Jereissati. É a partir destes pressupostos que se coloca a seguinte hipótese de trabalho: a de que as políticas de TICs nas gestões de Cid Gomes e Camilo Santana, situados mais à esquerda do espectro político do que os seus antecessores, estariam voltadas não apenas para a eficácia e a eficiência da política pública, mas também para o fortalecimento dos processos democráticos de participação e de deliberação desta política.

Para da conta deste problema, optou-se por fazer uma análise documental, tanto interna, que procura extrair as linhas fundamentais e secundárias dos documentos, quanto externa, contextualizando-os dentro da lógica política que lhes originou (DUVERGER, 1962). Para tanto, realizou-se um levantamento documental referente aos atos administrativos, portarias, leis e decretos estaduais, instruções normativas, mensagens legislativas e planos de governos que revelassem o uso e desenvolvimento das tecnologias da informação e comunicação, nos governos do Ceará no período compreendido entre 2007 e 2018.

0 artigo divide-se em três partes seguidas das considerações finais. Na primeira e na segunda, aborda-se os governos Cid Gomes, e na terceira, o governo Camilo, sempre focando o processo de implementação das políticas de TICs e de suas consequências para a gestão pública como um todo.

\section{O primeiro governo Cid Gomes: um novo ciclo político, uma nova agenda para as TICs (?)}

Na disputa eleitoral de 2006, Cid Gomes, então filiado ao PSB, e candidato pela coligação "Ceará vota para vencer" reunindo partidos de centro e de esquerda (PSB, PT, PC do B, PMDB, PV, PHS, PMN, PP e PRB), é eleito, no primeiro turno, para o governo do Estado do Ceará. Sua vitória representou o fim da hegemonia política capitaneada por Tasso Jereissati do Partido da Social Democracia Brasileira (PSDB), que durara vinte anos, e que foi responsável por um processo de modernização da máquina pública e da economia 
cearenses que tornou-se referência no contexto nacional por antecipar a reforma administrativa que iria se dar com o governo de Fenando Henrique Cardoso, também do PSDB (BARBALHO, 2007; GONDIM, 1998; NOBRE, 2008; PARENTE; ARRUDA, 2002).

A campanha de Cid Gomes baseou-se no discurso de que o Ceará precisaria dar um grande salto de desenvolvimento "em direção a uma sociedade justa e solidária, capaz de resgatar a dignidade da maioria de nossa população ainda excluída dos avanços e conquistas da sociedade contemporânea" (GOMES; PINHEIRO, 2006, p. 4). A estratégia de marketing político estava alinhada às transformações no âmbito da política nacional iniciadas em 2003 com o governo Lula, quando foram incrementados os processos de desenvolvimento e implementação de políticas públicas com a participação dos cidadãos. 0 candidato acentuava, tal como fizera Jereissati décadas atrás, "a ideia de um novo jeito de fazer política, com participação popular e apoio de importantes parceiros, como o governo federal, elegendo o desenvolvimento econômico com inclusão social como prioridade" (MONTE, 2017, p. 108).

Diante de um contexto nacional e estadual favorável, uma vez eleito, Cid Gomes conquistou uma bancada de sustentação com maioria absoluta na Assembleia Legislativa o que lhe proporcionou uma gestão tranquila diante da ausência de uma oposição organizada, relevante numericamente e capaz de fazer frente aos projetos do governador (CUNHA, 2012). Com isto, o governo pôde implementar sua política sem maior resistência por parte do poder legislativo. Por sua vez, pelo menos nas áreas de saúde, educação e agricultura, não houve descontinuidade administrativa e orçamentária (interrupções de obras, projetos e programas), em relação ao governo anterior (BRITO, 2015), o que sinaliza que a ruptura entre os dois grupos políticos não significou reordenamentos radicais na lógica da gestão pública estadual.

Em relação às TICS, a primeira medida do governo Cid Gomes foi a implementação de uma reforma administrativa que, entre outras consequências, reorganizou as ações estratégicas relacionadas ao uso destas tecnologias, alocando o Conselho Superior de Informática (CSI) na Secretaria do Planejamento e Gestão (SEPLAG), secretaria responsável pela coordenação dos processos de definição dos programas e atividades governamentais que eram traduzidos em planos orçamentários. Nesse pacote, a Empresa de Tecnologia da Informação do Estado do Ceará (ETICE), vinculada à SEPLAG e integrante do CSI, teve as suas atribuições redefinidas, passando a ser responsável por funções operacionais de suporte técnico e de gestão estratégica, destacando-se a coordenação do governo eletrônico com o objetivo de apoiar e fomentar o uso da internet para maior transparência e melhoria dos serviços prestados ao cidadão.

O governo, em seu primeiro ano, estabeleceu algumas metas-chave para o desenvolvimento e a disseminação do uso das TICs, que passavam por três grandes áreas de atuação: pela infraestrutura de comunicação digital existente no estado, pelo desenvolvimento de sistemas e programas de TI e pela capacitação dos colaboradores estaduais e da população civil. Para a nova gestão, os serviços de comunicação eram precários, de baixa qualidade e de custo elevado, e isso se dava em virtude de pouca concorrência na oferta dos serviços digitais, que estavam restritos às principais cidades do cearenses (CEARÁ, 2008).

A partir dessa premissa, o governo estabeleceu o que viria a se tornar o mais importante projeto de tecnologia da informação e comunicação da história do Ceará, o projeto Cinturão Digital (CDC). Este projeto estava sob responsabilidade da ETICE e tinha por finalidade a construção de um rede de fibra óptica estadual, com cobertura inicial de $82 \%$ da área urbana cearense até o final de 2009, para atender às demandas e ofertas dos serviços públicos estaduais nas plataformas digitais e para ofertar o acesso à rede mundial 
de computadores para os usuários cearenses de baixa renda (SILVA, 2014). Outra iniciativa importante foi a expansão da capacidade de tráfego e de dados da Rede Governamental que passou a conectar em alta velocidade através de cabos de fibra óptica interligados $90 \%$ dos órgãos estaduais (CEARÁ, 2008; 2009).

Estas medidas de melhoria da infraestrutura da rede computacional do estado foram importantes para o amadurecimento do uso das ferramentas de TIC em todas as instâncias da administração estadual, proporcionando mais alternativas para a inovação e ampliação da oferta dos serviços públicos via internet. Várias ações foram implementadas com o objetivo de potencializar a utilização da internet como um espaço de troca de informação entre as unidades administrativas e o cidadão-usuário, como também um ambiente para divulgação e prestação de contas das ações governamentais.

Assim, o governo orientou que a Controladoria Geral do Estado (CGE-CE) tomasse as medidas necessárias que garantissem o acesso do cidadão aos serviços públicos, e para tanto criou o Portal da Transparência através do qual o usuário poderia consultar as informações sobre as receitas e despesas orçamentárias estaduais, permitindo um nível de fiscalização das ações públicas e aumentando a transparência da gestão estadual (CEARÁ, 2009). Contudo, o acesso às informações estava comprometido, tanto pela difícil navegabilidade - dificuldade para encontrar as informações no portal - , como pela complexidade do entendimento técnico dos dados apresentados, distanciando o usuário do ambiente (SOUZA et al, 2019).

A preocupação do governo em estabelecer ações programáticas de inclusão digital - que envolveram áreas estratégicas diferentes, a exemplo da educação, com a distribuição de computadores para professores e escolas; da ação social, com o projeto Primeiro Passo Digital, e da ciência e tecnologia, com as "ilhas digitais" - não foi suficiente para reduzir a enorme fratura digital que existe no estado ${ }^{1}$. As ações de TIC voltadas para a eficiência e otimização dos recursos públicos (gestão fiscal) foram mais efetivas, contribuindo com outras ações de governo que se relacionavam com os ajustes fiscais e orçamentários para o desenvolvimento econômico do estado, que cresceu significativamente no período (MAIA; BOTELHO, 2007).

É possível afirmar que o primeiro governo Cid foi um "governo tecnológico", pois investiu com esforços na construção de infraestruturas para a comunicação digital e no desenvolvimento de soluções estratégicas de tecnologias de informação e comunicação para a consecução dos programas e ações do governo (PRADO et al., 2012; DINIZ, 2005; REINHARD; DIAS, 2005), ainda que se tenha observado ações em consonância com os requisitos para e-transparência e accountability, que possibilitaram um certo nível de interação entre o governo e a sociedade, dentro dos patamares das práticas nacionais, sendo elementos fundamentais e necessários para uma transição orientada ao desenvolvimento da democracia digital (MARQUES, 2004).

\footnotetext{
1 No ano de 2005, somente 6,9\% dos domicílios cearenses tinham computadores em casa, e destes, somente $4,4 \%$ tinham acesso à internet, e 12,9\% das pessoas, pertencentes à população com 10 anos ou mais, utilizaram a internet (IBGE, 2007). Os dados para 2011 apontam que estes números melhoraram consideravelmente 22,9\% de domicílios com computadores, $18,5 \%$ com computador acessando a internet, e 33,4\% das pessoas utilizaram a internet. Ainda assim, ficou na $23^{a}$ posição do ranking das unidades federativas com domicílios com computadores, e na $23^{a}$ posição com computadores que tinham acesso à internet. No ranking nacional dos usuários com acesso à rede mundial de computadores, o estado do Ceará apareceu na 24a posição, com um dos menores índices de participação, 33,4\%, abaixo da média nacional, que foi de 44,5\%, ficando à frente somente de Pará, Piauí e Maranhão (IBGE, 2013).
} 


\section{0 segundo governo Cid e as TICs: continuidades e novidades}

Cid Gomes foi reeleito governador do Ceará em 2010, como candidato da coligação "Por um Ceará melhor para todos" (PSB, PT, PMDB, PC do B, PDT, PSC e PRB) vencendo com certa facilidade os seus opositores no primeiro turno, com $61,27 \%$ dos votos válidos. Como era de se esperar, a proposta era a de continuísmo das políticas implementadas até então, com os devidos ajustes - tanto que o plano de governo do candidato tinha apenas dez páginas (MONTE, 2017).

Dentro desse "clima de continuidade", Cid Gomes deu prosseguimento às ações governamentais norteadas pelos três eixos definidos em 2011 (Sociedade Justa e Solidária; Economia para uma Vida Melhor; e Governo Participativo, Ético e Competente) visando o desenvolvimento socioeconômico com responsabilidade fiscal, a austeridade e eficiência da máquina administrativa e a inserção de elementos de princípios participativos (CEARÁ, 2011b).

No que diz respeito às TICs, a segunda gestão Cid reafirma o papel destas tecnologias como instrumentos importantes para a construção estratégica de políticas públicas que transformem a realidade socioeconômica do Ceará (CEARÁ, 2012). 0 uso das TICs foi potencializado em todos os três eixos citados acima, com ênfase para a área de planejamento e gestão, que priorizou o desenvolvimento tecnológico das secretarias e seus órgãos vinculados. A ETICE passou a ser a empresa responsável pela gestão da infraestrutura da rede governamental, das redes internet, intranet e extranet, como também responsável por proporcionar a integração de todos os órgãos no CDC (CEARÁ, 2011b).

Com a perspectiva de ampliar a oferta e o uso da banda larga no território cearense, o governo instituiu em 2011 o Programa Estadual de Banda Larga (PEBL) estabelecendo objetivos estratégicos de atuação por meio do CDC, entre os quais massificar o acesso à internet; promover a inclusão digital; ampliar os serviços de Governo Eletrônico; e capacitar a população para o uso das tecnologias de informação (CEARÁ, 2011b). Este programa pode ser considerada como um dos mais importantes do segundo governo Cid, uma vez que, para além da interconexão dos órgãos da administração pública, possibilitou a disseminação e expansão do CDC no território cearense para os setores públicos e privados.

Considerando cumprir as exigências previstas na Lei de Acesso à Informação, o governo regulamentou o Sistema de Ouvidoria de modo a torná-lo um canal de intermediação e possibilitar ao cidadão contribuir com a implementação e avaliação das políticas e serviços públicos. O Sistema ficou sob coordenação da CGE-CE que passou a ter, entre outras competências, disponibilizar canais de atendimento ao cidadão, incluindo aqueles propiciados pelas TICs e gerenciar de um novo Portal da Transparência (CEARÁ, 2013; MELO, 2012). Estas medidas consolidaram o papel da internet como canal privilegiado para divulgação e prestação de contas das ações governamentais cearense.

Na versão de 2012, o Portal da Transparência trouxe novas funcionalidades e, entre elas, o "Banco de Ideias", um ambiente de interação online para captar as sugestões dos internautas sobre serviços, ações, programas, inovações etc., para que estas fossem encaminhadas para as instâncias governamentais competentes. Foi a primeira experiência do governo estadual que pode ser considerada como e-participação e anterior, inclusive, ao Participa Brasil e ao Dialoga Brasil do Governo Federal (BARBALHO et al, 2017)

No último ano do governo Cid, verificou-se, a partir dos dados oficiais, um crescimento nos indicadores de TIC relacionados ao uso da internet (CEARÁ, 2015a). No entanto, mesmo tendo crescido os números em relação à aquisição de computadores por 
domicílios, saindo de 7,0\% dos domicílios particulares permanentes em 2005 (CEARÁ, 2007a) para 30,6\% em 2014 (CEARÁ, 2016a), e de 4,5\% dos computadores domiciliares ligados à internet em 2005 para 25,5\% no ano de 2014, o estado não conseguiu traduzir seu investimento nas infraestruturas de TIC em números de desenvolvimento socioeconômico, uma vez que figura entre os de menor desempenho de acesso à internet na pesquisa PNAD2014.

O Ceará ficou à frente somente de dois estados do Nordeste e um do Norte, no quesito de propriedade do bem "computador" por domicílios, e à frente de quatros estados do Norte e dois do Nordeste no quesito de computadores domiciliares ligados à internet. 0 estado ficou em 15을 colocado no ranking nacional no acesso à internet por banda larga fixa, com $62,2 \%$ dos domicílios, e o $18^{\circ}$, com $63,5 \%$ com o acesso à internet via banda larga móvel.

\section{0 governo Camilo Santana e a e-participação}

Camilo Santana, deputado estadual pelo PT e secretário nos dois governos Cid, foi escolhido pelo grupo político dos Ferreira Gomes, cujas principais lideranças estavam filadas ao PROS, para disputar as eleições para governador em 2014. Camilo venceu no segundo turno, com uma pequena margem de diferença $(53,35 \%)$, à frente da coligação "Para o Ceará seguir mudando", reunindo 18 partidos de diferentes espectros programáticos: PT, PROS, PCdoB, PDT, PSD, PHS, PMN, PP, PSC entre outros. Concorrendo nos dois turnos com Eunício Oliveira, do PMDB, partido da base do governo federal, Camilo não contou com o apoio explícito de Lula e Dilma, com isso, "pela primeira vez, o alinhamento que tanto beneficiara o grupo dos Ferreira Gomes estava comprometido, ampliando ainda mais as possibilidades de competição" (MONTE, 2017, p.113). Diante da queda de popularidade do governo Cid, Camilo, que não podia deixar de apontar alguma continuidade com os governos anteriores, se comprometendo em manter as ações estruturantes (siderúrgica, metrô etc), "reconhecia a necessidade de dialogar mais com a sociedade" (MONTE, 2017, p.114)

O programa do candidato Camilo, intitulado "Os 7 Cearás", se estruturava nos seguintes eixos: 1- Ceará da Gestão Democrática por Resultados; 2 - Ceará Acolhedor; 3 Ceará de Oportunidades; 4 - Ceará Sustentável; 5 - Ceará do Conhecimento; 6 - Ceará Sustentável, e 7 - Ceará Pacífico. 0 documento afirmava a participação ativa dos cidadãos como a melhor forma de estabelecer uma relação de compromisso entre o governo e a sociedade para a construção e implementação de políticas que tenham objetivos e interesses públicos e ressaltava a importância do planejamento participativo como uma ferramenta estratégica para a construção e definição das políticas públicas estaduais. Segundo consta no documento, o programa foi elaborado a partir de um processo de discussão e compilação de várias propostas apresentadas em conferências e seminários de validação, que foram realizados durante e após o período eleitoral, finalizados antes do início do novo governo (SANTANA, 2014).

Nesse contexto, as TICs foram consideradas como estratégicas para a consecução das metas e com esse fim o governo decidiu estruturar o Sistema Estadual de Tecnologia da Informação e Comunicação (SETIC), um organismo intersetorial, composto pela Secretaria de Ciências e Tecnologia (SECITECE), pela ETICE, pela SEPLAG e os órgãos setoriais de TIC de cada uma das secretarias e das outras instituições do governo. O SETIC tinha como propósito, criar, planejar, integrar, articular e executar as políticas públicas de TIC no estado. 0 governo definiu ainda como prioridade, no eixo do "Ceará do Conhecimento", o fortalecimento da ETICE para o cumprimento de sua missão como órgão normativo e consultor, como também a expansão do CDC para atender a todos os municípios cearenses 
com serviços de banda larga, proporcionando dessa forma, a viabilização dos programas governamentais nas demais unidades administrativas instaladas no estado (SANTANA, 2014).

Como demonstração de interesse por uma maior participação dos cidadãos nos serviços e negócios do estado através da internet, o novo governo sinalizou que iria ampliar "o Governo Eletrônico de forma obter a excelência na entrega de serviços ao cidadão, com maior agilidade, transparência, acesso à informação e interação sociedade-governo (bidirecional)" (SANTANA, 2014, p. 18). De fato, o governo pôs em prática várias medidas de ampliação do uso das TIC nas unidades administrativas do estado durante os quatro anos de gestão (CEARÁ, 2016; 2017a; 2018; 2019), priorizando o desenvolvimento de sistemas informatizados voltados para a plataforma web, que permitissem, quando fosse o caso, uma maior participação do cidadão-usuário nos serviços ofertados pela administração pública. A diretriz estabelecida no período foi a de adaptar os serviços de atendimento ao público para a plataforma internet. A medida impactou as diversas áreas do governo, na qual as secretarias e órgãos que ofertavam serviços com atendimento ao público tiveram que melhorar e/ou adaptar suas estruturas à nova plataforma.

As secretarias tradicionais e com o maior leque de oferta de serviços, disponibilizaram, quase na sua totalidade, estes serviços na web, a exemplo da Fazenda com os serviços de regularização e quitação de taxas e tributos via a nova plataforma digital; da Educação - com matriculas online e testes de nível de conhecimentos e conteúdos na web; da Saúde - com a disponibilização e acompanhamento dos serviços de internamento; na Segurança Pública - sistema de informações policiais pela web. A Controladoria e Ouvidoria Geral do Estado, além de disponibilizar os seus serviços de ouvidoria e de acesso à informação, procedeu com a gestão das informações de transparência dos outros órgãos estaduais para serem disponibilizados através do Portal da Transparência do estado.

A potencialização do portal proporcionou ao governo uma ótima avaliação na 3a Edição da Escala Brasil de Transparência, promovida pela Controladoria Geral da União, para identificar o nível de transparência nos estados e municípios. 0 portal do governo recebeu a nota máxima na avaliação do cumprimento dos dispositivos da Lei de Acesso à Informação ${ }^{2}$. Observou-se ainda que o governo estimulou que a população interagisse com a ferramenta e se manifestasse sobre os serviços e políticas ofertadas na gestão, registrando mais de 350 mil acessos no ano de 2017, totalizando 1,45 milhões de acessos desde a sua implementação no final de 2012.

O ambiente do Banco de Ideias permaneceu com a mesma funcionalidade dentro do Portal da Transparência, mantendo sua proposta de ambiente de participação online de interação recíproca entre estado e sociedade, coletando sugestões de ações e/ou políticas públicas para serem tratadas dentro das instâncias do governo. Todas estas medidas do governo cearense convergiram com os processos de desenvolvimento e maturação do governo eletrônico como instrumento de transparência e accountability (MEDEIROS, 2004).

Na reavaliação do Plano Plurianual (PPA), no final de 2017, foram consideradas algumas alterações para os programas e ações planejadas para o ano seguinte entre as quais o estabelecimento de uma nova meta, a implementação do Sistema Cearense de Participação Cidadã, uma estrutura institucionalizada com objetivo de incentivar, desenvolver e integrar, sistemicamente, os eixos de participação cidadã aderentes à estrutura governamental, de forma a contribuir para o fortalecimento da gestão pública por resultados (CEARÁ, 2017b).

2 Para maiores detalhes consultar o site da Controladoria Geral da União: <https://www.cgu.gov.br/assuntos/transparencia-publica/escala-brasil-transparente>. Acesso em: 05 maio 2018. 
No modelo sistêmico foram previstas seis dimensões (PPA, Setorial, Territorial, Ouvidoria, Longo Prazo e Suporte) para a incorporação da participação dos cidadãos no planejamento e monitoramento das ações, projetos e programas de governo (CEARÁ, 2017c). Destaca-se a dimensão de Suporte, que previu a integração de três processos interrelacionados: a comunicação, a capacitação e uma plataforma digital, para proporcionar a interconexão e articulação entre as demais dimensões participativas. Para a plataforma digital do sistema foi prevista a construção de espaços virtuais para a divulgação de informações, conferências, formação de comunidades, fóruns de debates e áreas de capacitação, elementos basilares para o desenvolvimento da e-participação. Não obstante, até o final do levantamento de dados desta pesquisa, início de dezembro de 2018, esta plataforma virtual não havia sido implantada.

Outra medida importante para o desenvolvimento do uso das TICs no estado foi a definição do Hub de Tecnologia da Informação e Comunicação (HTIC). Trata-se de um programa governamental institucionalizado no final de 2018, que visa o desenvolvimento das tecnologias de informação e comunicação nos domínios da administração pública cearense. 0 programa tem por missão promover as novas tecnologias digitais, buscando a efetividade do custeio e investimento realizados em TIC, como também disponibilizar as infraestruturas de dados e de rede para acesso em alta velocidade à internet, com o objetivo de proporcionar uma maior sinergia entre os atores estaduais na oferta dos serviços públicos. Esta ação foi destacada para registrar a preocupação do governo em avançar no processo de atualização tecnológica e de otimizar do uso das estruturas de TIC, priorizando, neste caso, a expansão e utilização do Cinturão Digital.

Contudo, segundo a PNAD de acesso à internet de 2015, a última pesquisa completa com indicadores sobre o tema realizada pelo IBGE, o percentual de domicílios cearenses que possuíam computadores sofreu uma queda, passando de 30,6\% em 2014, para 27,9\% em 2015. 0 número de computadores domiciliares com acesso à internet também sofreu uma redução, passando de 25,5\% para 23,5\% (CEARÁ, 2016b). Os dados do PNAD estão diretamente relacionados com uma questão central do debate sobre o acesso às TICS pelo conjunto da sociedade que é a condição socioeconômica e de desenvolvimento humano na qual o cidadão está inserido. Os serviços de inovação tecnológica prestados pelo governo são quase que na sua totalidade implementados no padrão de navegação pela web, demandando dos cidadãos-usuários computadores com browsers ${ }^{3}$ para poder prover os serviços do estado e consequentemente contabilizar os seus resultados.

Ora, o Ceará figura entre os estados mais pobres do país, com uma das menores renda per capita e com um dos maiores índices em desigualdade social. Um cenário que aumenta a necessidade de se encontrar alternativas para a ampliação da acessibilidade e de se desenvolver softwares mais amigáveis para proporcionar uma maior usabilidade e qualidade dos serviços disponibilizados pela internet.

A gestão Camilo Santana se propôs a ser um governo transparente e participativo, ao mesmo tempo que tomou decisões de modernização das estruturas administrativas através da inovação tecnológica, acreditando no uso das TICS para melhorar os resultados fiscais e administrativos da gestão pública. Com isso, o governo manteve uma estrutura de gestão centralizada, visando a otimização e utilização racional das TICs pelas instituições estaduais, vindo, ao final de 2018, aprovar uma legislação específica para o controle de aquisição e uso de hardwares e softwares nas instâncias do estado.

Em outras palavras, a decisão de universalização dos serviços através da internet foi a medida que o governo encontrou para proporcionar uma maior aproximação do cidadão

3 Softwares para navegação na web. 
com os serviços do estado, abrindo um espaço de interação com o usuário, mas nenhuma outra ação de inovação do uso das TICs para a internet, para além da carta de serviços dos órgãos e secretarias e do Portal da Transparência, foi observada pela pesquisa.

\section{Considerações finais}

Os projetos de democracia digital, por meio do uso das TICs, almejam cobrir os déficits percebidos no exercício da democracia presencial, posto que estas tecnologias proporcionaram uma gradação de soluções voltadas às questões relacionadas às tensões existentes em torno da representação política (GOMES, 2007). Contudo, considerando a polissemia do termo [democracia digital], algumas questões centrais se colocam, entre elas, a que foi objeto de maior atenção nesse artigo: quais suas dimensões de uso e relacionamento com os atores políticos envolvidos? A pergunta é pertinente pois as TICs só podem funcionar a favor do fortalecimento da democracia a partir da vontade das esferas civil e política em construir os mecanismos que possibilitem as alterações a favor ou contra da sua dinamização.

Para tanto, faz-se necessário capacitar os atores envolvidos (governamentais e nãogovernamentais) para compreender e utilizar os recursos e informações disponibilizados. Como defende Jamil Marques (2008), as instituições governamentais devem levar em consideração, nas suas ações programáticas, mecanismos participativos que possibilitem um novo comportamento do cidadão, permitindo o seu acesso à informação e estimulando sua participação política através de canais de comunicação interativos. Isso implica em acessos mais rápidos para o acompanhamento e levantamento das informações da prestação de contas, permitindo, também, o uso de canais diretos de relacionamento, sob a ótica da transparência, participação e controle social das políticas públicas. Caso contrário, a implementação de TICs não resultarão em uma experiência de democracia digital. As interfaces tecnológicas desenvolvidas precisam garantir ganhos democráticos, mas somente ganhos de eficiência tecnológica e/ou administrativa.

Ao avaliar as políticas de TICs dos governos Cid e Camilo, percebe-se a evolução no uso destas pelo estado do Ceará, constatando-se que, a cada gestão, se avançou um pouco mais na qualidade da infraestrutura tecnológica de informática instalada e no quadro de pessoal técnico envolvido para a execução dos serviços do governo, o que revela, por exemplo, o pioneirismo da utilização da Rede Nacional de Pesquisa para interligar os equipamentos do estado na internet. Esta ação contribuiu para a formatação do plano da rede coorporativa estadual e do Cinturão Digital, projetos que alavancaram o desenvolvimento dos novos serviços do governo, que hoje são ofertados pela internet.

Observou-se ainda que os governos estavam comprometidos com a política econômica de equilíbrio fiscal e de desenvolvimento econômico, baseado em projetos infraestruturais e de industrialização, mas também com políticas de investimento em projetos e ações de desenvolvimento social, prometidas nas campanhas eleitorais. No entanto, a despeito do avanço nesse área, em comparação com os governos anteriores, não se pode afirmar que a democracia digital tenha sido o fim último desse grande investimento em TICs.

Certamente alguns déficits foram superados, como o maior acesso à internet por parte da população, mesmo no interior do estado. Mas não a ponto de modificar a dinâmica da relação com a maior parte da sociedade civil, a despeito da existência dos mecanismos participativos e da existência de recursos facilitadores de transparência e accountability. Pode-se concluir que, no balanço geral, teve-se alguns ganhos democráticos, mas aqueles voltados à eficiência administrativa foram de fato o principal foco da política de TICs. 


\section{Referências bibliográficas}

ADORNO, T.; HORKHEIMER, M. Sociológica. Madri: Taurus, 1986.

AVRITZER, Leonardo; SANTOS, Boaventura de Sousa. Para ampliar o cânone democrático. In Santos, Boaventura de Sousa (org). Democratizar a Democracia: os caminhos da democracia participativa. Rio de Janeiro: Civilização Brasileira, p. 39-82, 2002.

BARBALHO, Alexandre. Os modernos e os tradicionais: cultura política no Ceará contemporâneo. Estudos de Sociologia, v. 12, n. 22, p. 27-42, 2007.

.; DO VALE, Carolina; CORDEIRO, Marília. A Cultura na Plataforma On-Line Dialoga

Brasil. Pensamento \& Realidade. Revista do Programa de Estudos Pós-Graduados em Administração-FEA. ISSN 2237-4418, v. 30, n. 4, p. 16, 2017. Disponível em: <https://revistas.pucsp.br/index.php/pensamentorealidade/article/view/33938/24801> . Acesso em: 30 jan. 2018.

BOBBIO, Norberto. O Futuro da Democracia. 14a Edição, São Paulo: Paz e Terra, 2017.

BRITO, Cléa Sabino de Matos. Análise de continuidade orçamentária no Estado do Ceará no período de 2004 a 2012: estudo de caso da mudança de governo Lúcio Alcântara para o de Cid Gomes. 2015. 80f. Dissertação (mestrado profissional) - Universidade Federal do Ceará, Programa de Pós Graduação em Economia, CAEN, Fortaleza-Ce, 2015.

CEARÁ. DESENVOLVIMENTO JUSTO E SOLIDÁRIO: "NOVO JEITO DE FAZER". Plano Plurianual 2008 - 2011, Vol. I. Fortaleza: Governo do Estado do Ceará - Secretaria de Planejamento e Gestão, 2007a.

Mensagem à Assembléia Legislativa 2008. Fortaleza: Governo do Estado do Ceará

- Secretaria de Planejamento e Gestão, 2008.

Mensagem à Assembleia Legislativa 2009. Fortaleza: Governo do Estado do Ceará - Secretaria de Planejamento e Gestão, 2009.

DESENVOLVIMENTO JUSTO E SOLIDÁRIO: "NOVO JEITO DE FAZER". Plano Plurianual 2012 - 2015, Vol. I. Fortaleza: Governo do Estado do Ceará - Secretaria de Planejamento e Gestão, 2011b.

DECRETO № 30.939/2012, de 10 de julho de 2012. Dispõe sobre a operacionalização do Portal da Transparência do poder executivo estadual e dá outras providências. Diário Oficial do Estado do Ceará, Fortaleza, CE, no 132, Série 3, ANO IV, 2012.

. Mensagem à Assembleia Legislativa 2013. Fortaleza: Governo do Estado do Ceará - Secretaria de Planejamento e Gestão, 2013.

Mensagem à Assembleia Legislativa 2015. Fortaleza: Governo do Estado do Ceará - Secretaria de Planejamento e Gestão, 2015a.

. Mensagem à Assembleia Legislativa 2016. Fortaleza: Governo do Estado do Ceará - Secretaria de Planejamento e Gestão, 2016.

. Mensagem à Assembleia Legislativa 2017. Fortaleza: Governo do Estado do Ceará

- Secretaria de Planejamento e Gestão, 2017a. 
Plano Plurianual 2016 - 2019: LEI DE REVISÃO 2018-2019 - Lei no 16.450, 14 de dezembro de 2017, Vol. I. Fortaleza: Governo do Estado do Ceará - Secretaria de Planejamento e Gestão, 2017b.

Projeto Participação Cidadã: Produto 3 - Modelo de Gestão Participativa no Planejamento e Monitoramento das Políticas, Planos e Projetos do Governo do Estado do Ceará. Fortaleza: Governo do Estado do Ceará, 2017c.

Mensagem à Assembleia Legislativa 2018. Fortaleza: Governo do Estado do Ceará - Secretaria de Planejamento e Gestão, 2018.

Mensagem à Assembleia Legislativa 2019. Fortaleza: Governo do Estado do Ceará - Secretaria de Planejamento e Gestão, 2019.

COLEMAN, S.; SPILLER, Josephine. Exploring new media effects on representative democracy. The journal of legislative studies, v. 9, n. 3, p. 1-16, 2003.

CUNHA, B. S. B. Poder e consentimento: Formação e manutenção da base de sustentação do governo Cid Gomes (2007-2010). 2012. 89 f. Monografia (Graduação em Ciências Sociais) - Departamento de Ciências Sociais, Centro de Humanidades, Universidade Federal do Ceará, Fortaleza, 2012.

DINIZ, Vagner. A história do uso da tecnologia da informação na gestão pública brasileira através do CONIP - Congresso de Informática Pública. In: Congreso internacional del clad sobre la reforma del estado y de la administración pública. p. 10, 2005. Disponível em: <http://siare.clad.org/fulltext/0052732.pdf> Acesso em: 09 set. 2017.

DUVERGER, Maurice. Ciência Política. Teoria e método. Rio de Janeiro: Zahar, 1962.

GONDIM, Linda. Clientelismo e modernidade nas políticas públicas: os "Governos das Mudanças" no Ceará (1987- 1994). Ijuí: Unijuí, 1998.

GOMES, C. F., PINHEIRO, F. Diretrizes para o Plano De Governo - Da Coligação, Ceará Vota Para Crescer. 2007. Disponível em:

<http://www2.seplag.ce.gov.br/content/aplicacao/SEAD/seplan/downloads/DIRETRIZE S_PARA_O_PLANO_DE_GOVERNO.pdf $>$. Acesso em: 24 set. 2017.

GOMES, Wilson. Uma agenda de pesquisa sobre Democracia Digital. IVJornadas de Comunicação e Democracia entre grupos de pesquisa da UFBA e UFMG, Belo Horizonte: UFMG, 2007.

Participação Política Online: Questões e hipóteses de trabalho. In: Internet e Participação Política no Brasil. (org) MAIA, Rousiley; GOMES, Wilson, Porto Alegre, Editora Sulinas, p. 19-46, 2011.

MAIA, Rousiley C. M.; GOMES, W; MARQUES, F.P.J.A. (org). Internet e Participação Política no Brasil. Porto Alegre: Sulina, 2011.

MAIA, J. N. B; BOTELHO, D. C. Gestão Governamental no Ceará, 1979-2014: da Crise de 1986 ao Ajuste Fiscal e Reforma do Estado. Fortaleza: Expressão Gráfica e Editora, 2017.

MARQUES, Francisco Paulo Jamil Almeida. Dimensões da ciberdemocracia - conceitos e experiências fundamentais. 2004. 201p. Dissertação de mestrado (Programa de PósGraduação em Comunicação e Cultura Contemporâneas) - Faculdade de Comunicação, 
Universidade Federal da Bahia, Salvador. Disponível em:

<https://repositorio.ufba.br/ri/handle/ri/11302?mode=full\&submit_simple=Mostrar+re gistro+completo+do+item>. Acesso em: 12 abr. 2017.

Participação política e Internet: Meios e oportunidades digitais de participação civil na democracia contemporânea, com um estudo do caso do estado brasileiro, 2008. 498p. Tese (Doutorado em Comunicação e Cultura Contemporâneas) - Faculdade de Comunicação, Universidade Federal da Bahia, Salvador. Disponível em: <http://www.repositorio.ufc.br/bitstream/riufc/671/1/2008_tese_\%20fpjamarques.pdf >. Acesso em: 12 abr. 2017.

MEDEIROS, P. H. Governo eletrônico no Brasil: aspectos institucionais e reflexos na governança. Dissertação (Mestrado em Administração) — Universidade de Brasília (UnB), Brasília, 2004.

MELO, Rogério Mourão. 0 controle dos recursos públicos pela controladoria do poder executivo do estado do Ceará: as ações da controladoria e ouvidoria geral do estado do Ceará no período de 2006 a 2010. (Dissertação). Mestrado Profissional em Planejamento e Políticas Públicas, Universidade Estadual do Ceará. Fortaleza, 2012.

MONTE, Cleyton. As estratégias eleitorais dos Ferreira Gomes e os alinhamentos na política cearense contemporânea (2006-2014). Conexão Política, Teresina v. 6, n. 2, 97 - 119, jul./dez. 2017

MONTE, Francisca Silvania de Sousa. Os paradigmas da modernização do estado do Ceará e o processo de construção da Barragem do Castanhão. Revista Brasileira de Estudos Urbanos e Regionais, [S.l.], v. 10, n. 1, p. 87, maio 2008. Disponível em: $<$ http://rbeur.anpur.org.br/rbeur/article/view/193>. Acesso em: 06 abr. 2018.

NOBRE, Maria CQ. Modernização do atraso: a hegemonia burguesa do CIC e as alianças eleitorais da "Era Tasso". Tese de Doutorado. Tese (Doutorado em Sociologia)-Universidade Federal do Ceará, Fortaleza, 2008.

PARENTE, J., ARRUDA, J. M. (orgs.). A era Jereissati. Modernidade e mito. Fortaleza, Demócrito Rocha, 2002.

PRADO, Otávio; RIBEIRO, Manuella Maia; DINIZ, Eduardo. Governo eletrônico e transparência: olhar crítico sobre os portais do governo federal brasileiro. Estado, sociedade e interações digitais: expectativas democráticas, p. 13-39, 2012.

REINHARD, Nicolau; DIAS, Isabel de Meiroz. Categorization of e-gov initiatives: a comparison of three perspectives. 2005. Disponível em: < https://cladista.clad.org/bitstream/handle/123456789/3631/0052733.pdf?sequence=1 \&isAllowed=y >. Acesso em: 04 nov. 2017.

SANTANA, Eudoro et al. Os 7 Cearás: Propostas para o Plano de Governo, Fortaleza, 2014.

SILVA, Alex Barros da. Inclusão digital e inovação social: o caso do cinturão digital do Ceará. Monografia (Bacharelado em Administração Pública) - Instituto Universidade Virtual, Universidade Federal do Ceará, Tauá, 2014.

SOUZA, Ramon Jorge de et al. Avaliação da Qualidade das Informações disponibilizadas no Portal da Transparência do Estado do Ceará. Encontros Bibli: revista eletrônica de 
biblioteconomia e ciência da informação, Florianópolis, v. 24, n. 54, p. 91-104, jan. 2019. Disponível em: <https://periodicos.ufsc.br/index.php/eb/article/view/15182924.2019v24n54p91/38075>. Acesso em: 30 mar. 2020. 